\title{
Naxibacter varians sp. nov. and Naxibacter haematophilus sp. nov., and emended description of the genus Naxibacter
}

Correspondence
Peter Kämpfer
peter.kaempfer@umwelt.
uni-giessen.de

The betaproteobacterial genus Naxibacter was described by $\mathrm{Xu}$ et al. (2005) and at present the genus comprises only one species, Naxibacter alkalitolerans. Phylogenetically, it is placed in the vicinity of Massilia, Telluria, Duganella and Janthinobacterium. The single strain of this species was isolated from a soil sample and shown to produce polyketide antibiotics (Xu et al., 2005). Another striking characteristic of this species was the detection of phosphatidylinositol mannosides in its polar lipid profile, which usually is a characteristic of Gram-positive bacteria; to the best of our knowledge, there is so far no other report of presence of this lipid in Gram-negative bacteria.

Strains CCUG $35299^{\mathrm{T}}$, CCUG 24677A, CCUG 48018, CCUG 49054, CCUG 48700A and CCUG $38318^{\mathrm{T}}$ were

The GenBank/EMBL/DDBJ accession numbers for the 16S rRNA gene sequences of strains CCUG 35299 ${ }^{\top}$ and CCUG 38318 ${ }^{\top}$ are respectively AM774587 and AM774589.

Results of two-dimensional TLC of the polar lipids of the type strains of the novel species and details of antibiotic susceptibility are available as supplementary material with the online version of this paper. isolated from various sources. Strain CCUG $35299^{\mathrm{T}}$ was isolated in 1996 from the eye of a 90-year-old man in Tromsö, Norway. Strains CCUG 48018 and CCUG 48700A were isolated from water in Sweden. Strain CCUG 24677A was isolated in 1989 in Stockholm, Sweden, from human blood. Strain CCUG $38318^{\mathrm{T}}$ was also isolated from human blood, of a 23-year-old man with multiple health problems in 1997. All strains were presumptively identified as Massilia-like and all showed beige-coloured colonies on nutrient agar (Oxoid) at $37^{\circ} \mathrm{C}$. Subcultivation for further analyses was done on tryptone soy agar (TSA; Oxoid) at $28{ }^{\circ} \mathrm{C}$ for $48 \mathrm{~h}$.

Gram-staining was performed as described by Gerhardt et al. (1994). Cell morphology was observed under a Zeiss light microscope at $\times 1000$, with cells grown for 3 days at $28{ }^{\circ} \mathrm{C}$ on TSA. The $16 \mathrm{~S}$ rRNA gene was analysed as described by Kämpfer et al. (2003). Phylogenetic analysis was performed using the ARB software package (Ludwig et al., 2004) and also the software package MEGA version 2.1 (Kumar et al., 2001) after multiple alignment of data by 
CLUSTAL_X (Thompson et al., 1997). Distances (distance options according to the Kimura-2 model) were calculated and clustering with the neighbour-joining, maximumparsimony and maximum-likelihood algorithms was performed by using bootstrap values based on 1000 replications. The almost-complete 16S rRNA gene sequences of all strains were compared by sequence similarity calculations after a neighbour-joining analysis. The results of these calculations indicated that the closest relative of strains CCUG $35299^{\mathrm{T}}$, CCUG 24677A, CCUG 48018, CCUG 49054 and CCUG 48700A was N. alkalitolerans (99.1-99.8\% similarity to the type strain). Strain CCUG $38018^{\mathrm{T}}$ showed $97.6 \%$ 16S rRNA gene sequence similarity to the type strain of $N$. alkalitolerans and $98.1 \%$ to CCUG $35299^{\mathrm{T}}$.

A phylogenetic tree is shown in Fig. 1. The branching pattern was confirmed by maximum-parsimony and maximum-likelihood analyses (data not shown).

For quinone, polar lipid and polyamine analyses, cells were grown on PYE medium (Busse et al., 2005). Quinone systems and polar lipid profiles were analysed according to Tindall (1990a, b) and Altenburger et al. (1996) and polyamine patterns as described by Busse \& Auling (1988) and Busse et al. (1997). The four strains CCUG $35299^{\mathrm{T}}$, CCUG 48700A, CCUG 24677A and CCUG $38318^{\mathrm{T}}$ exhibited typical betaproteobacterial quinone systems, with the predominant compound ubiquinone Q-8 (96.6-98.6\%) and minor amounts of ubiquinone Q-7 $(1.4-3.4 \%)$.

The predominant compounds of the polar lipid profiles of the four strains were identical. They consisted of the major compounds phosphatidylethanolamine, phosphatidylglycerol and diphosphatidylglycerol. In CCUG $35299^{\mathrm{T}}$ (see Supplementary Fig. S1a in IJSEM Online) and CCUG
24677A (results not shown), moderate amounts of an unknown polar lipid (L1) and an unknown phospholipid (PL1) and minor to trace amounts of two unknown aminolipids (AL1, AL2) and an unknown phospholipid (PL2) could be detected. Trace amounts of the unknown aminophospholipid APL1 (not indicated in Supplementary Fig. S1a) may be present as well but, due to its very low abundance, it is not visible on the chromatogram. The position is visible in Supplementary Fig. S1(b). Since strains CCUG $35299^{\mathrm{T}}$ and CCUG 24677A belong to the same species, as demonstrated by the results of DNA-DNA hybridizations (see below), this similarity demonstrates their close relatedness. The next phylogenetic neighbour (Fig. 1), strain CCUG 48700A, also shared an identical polar lipid profile (not shown). Strain CCUG $38318^{\mathrm{T}}$, which is more distantly related to the other species of the Naxibacter clade (Fig. 1), exhibited some striking differences. In its polar lipid profile (Supplementary Fig. S1b), significant amounts of the unknown aminophospholipid APL1, unknown aminolipid AL3 and a yellow spot could be detected. None of the four strains exhibited the presence of phosphatidylinositol mannosides or any other glycolipid. This observation was surprising, because the close relative $N$. alkalitolerans was reported to contain phosphatidylinositol mannoside in its polar lipid profile (Xu et al., 2005). Hence, we also analysed the profile of $N$. alkalitolerans (results not shown) and, in fact, we were not able to detect phosphatidylinositol mannosides or any other glycolipid in the profile of the type strain of this species. This result is in agreement with the present knowledge that this glycolipid is found in certain Grampositive taxa but not in Gram-negative taxa.

Strains CCUG 48700A, CCUG 24677A and CCUG $38318^{\mathrm{T}}$ showed polyamine patterns characteristic for betaproteobacteria, with the major compounds 2-hydroxyputrescine

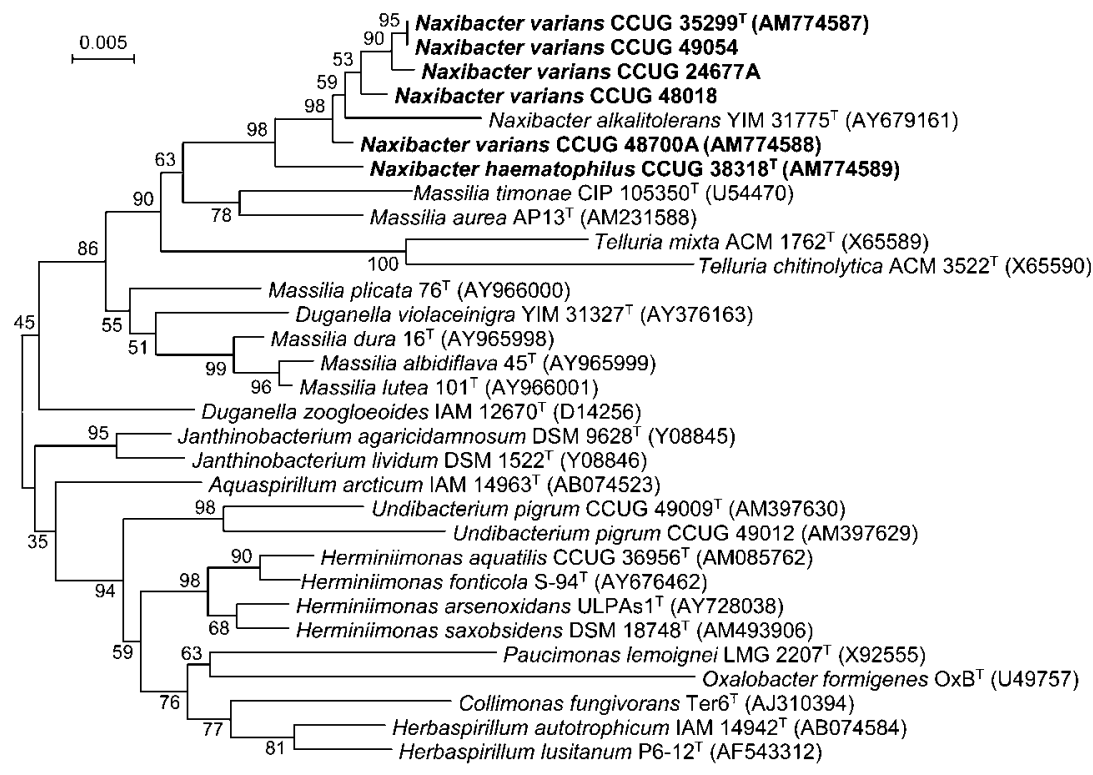

Fig. 1. Phylogenetic analysis based on $16 \mathrm{~S}$ rRNA gene sequences available from the European Molecular Biology Laboratory database (accession numbers in parentheses) constructed after multiple alignment of data by CLUSTAL_X (Thompson et al., 1997). Distances (distance options according to the Kimura-2 model) were calculated and clustering with the neighbour-joining method was performed by using the software package MEGA version 2.1 (Kumar et al., 2001). Bootstrap values based on 1000 replications are listed as percentages at branching points. Bar, 0.005 substitutions per nucleotide position. 
and putrescine. Other polyamines such as spermidine and spermine were always detected in smaller amounts and 1,3diaminopropane and cadaverine were detected in trace amounts in the pattern of CCUG $35299^{\mathrm{T}}$ only. Similar polyamine patterns were detected in related type strains Naxibacter alkalitolerans CCUG $50882^{\mathrm{T}}$ [ $\mu \mathrm{mol}$ (g dry weight $)^{-1}$ : 2-hydroxyputrescine, 39.4; putrescine, 60.1; spermidine, 11.5; spermine, 3.2], Massilia timonae CCUG $45783^{\mathrm{T}}$ (2-hydroxyputrescine, 24.0; putrescine, 74.4; spermidine, 4.1 ; spermine, 1.4) and Janthinobacterium agaricidamnosum CCUG $43140^{\mathrm{T}}$ (2-hydroxyputrescine, 37.3; putrescine, 137.5; cadaverine, 0.7; spermidine, 1.1; spermine, <1.0).

The fatty acid profiles of all strains obtained with the method described by Kämpfer \& Kroppenstedt (1996) are shown in Table 1. No pronounced differences in fatty acid profiles were found.

Results of the physiological characterization are given in the species description and in Table 2 (differential characters), obtained with methods described previously (Kämpfer et al., 1991). Sensitivity towards antimicrobial compounds was examined according to the disc-diffusion plate method but, due to poor growth on Mueller-Hinton agar, the tests were done on PYE (peptone-yeast extract) agar and incubated for 4 days at $28{ }^{\circ} \mathrm{C}$. The results are listed in the species descriptions and in Supplementary Table S1.

DNA-DNA hybridization experiments were performed with all strains and the type strain of Naxibacter alkalitolerans, CCUG $50882^{\mathrm{T}}$, using the method described by Ziemke et al. (1998) except that, for nick translation,

Table 1. Cellular fatty acid compositions (\%) of Naxibacter strains

Strains: $1, N$. alkalitolerans CCUG $50882^{\mathrm{T}} ; 2-6$, strains of $N$. varians sp. nov. (2, CCUG 48018; 3, CCUG 35299 ${ }^{\mathrm{T}}$; 4, CCUG 49054; 5, CCUG 24677A; 6, CCUG 48700A); 7, N. haematophilus sp. nov. CCUG $38318^{\mathrm{T}}$. -, Not detected.

\begin{tabular}{|lccccccc|}
\hline Fatty acid & $\mathbf{1}$ & $\mathbf{2}$ & $\mathbf{3}$ & $\mathbf{4}$ & $\mathbf{5}$ & $\mathbf{6}$ & $\mathbf{7}$ \\
\hline $\mathrm{C}_{10: 0}$ & 0.7 & 0.4 & 0.5 & 0.4 & 0.4 & 0.7 & 0.6 \\
$\mathrm{C}_{10: 0} 3-\mathrm{OH}$ & 6.2 & 3.6 & 4.0 & 4.5 & 4.1 & 5.3 & 4.7 \\
$\mathrm{C}_{12: 0}$ & 6.3 & 3.0 & 3.4 & 3.4 & 3.6 & 4.0 & 4.5 \\
$\mathrm{C}_{12: 0} 2-\mathrm{OH}$ & 2.0 & 1.3 & 1.8 & 1.8 & 1.4 & 2.3 & 1.5 \\
$\mathrm{C}_{14: 0}$ & 1.2 & 0.8 & 1.0 & 0.6 & 0.7 & 0.6 & 0.6 \\
$\mathrm{C}_{15: 0}$ & 0.8 & 0.5 & 0.4 & 0.6 & 0.6 & - & 0.3 \\
$\mathrm{C}_{16: 1} \omega 7 c^{\star}$ & 43.1 & 50.4 & 47.4 & 45.8 & 49.2 & 52.1 & 46.3 \\
$\mathrm{C}_{16: 0}$ & 30.0 & 32.0 & 31.9 & 32.2 & 33.3 & 22.3 & 28.6 \\
anteiso- $_{17: 1} \omega 9 c$ & 0.3 & - & - & - & - & - & - \\
iso-C $_{17: 1} \omega 9 c$ & - & 0.4 & 0.4 & 0.3 & - & 0.5 & - \\
$\mathrm{C}_{17: 0}$ cyclo & 1.3 & - & - & - & - & - & - \\
$\mathrm{C}_{18: 1} \omega 7 c$ & 6.9 & 7.5 & 8.4 & 9.2 & 6.5 & 12.2 & 12.7 \\
$\mathrm{C}_{18: 0}$ & 0.4 & 0.2 & 0.6 & 0.5 & - & - & 0.5 \\
\hline
\end{tabular}

${ }^{\star}$ Included in summed feature $3\left(\mathrm{C}_{16: 1} \omega 7 c\right.$ and/or iso- $\left.\mathrm{C}_{15: 0} 2-\mathrm{OH}\right)$.
Table 2. Differential phenotypic properties of Naxibacter species

Strains: 1, N. alkalitolerans CCUG $50882^{\mathrm{T}} ; 2-6$, N. varians strains $(2$, CCUG 48018; 3, CCUG 35299 ${ }^{\mathrm{T}}$; 4, CCUG 49054; 5, CCUG 24677A; 6, CCUG 48700A); 7, N. haematophilus CCUG 38318 ${ }^{\mathrm{T}}$. +, Positive; $(+)$, weakly positive; -, negative; ONPG, $o$-nitrophenyl $\beta$-Dglucoside. All strains were positive for utilization of maltose, malate, fumarate and pyruvate and hydrolysis of $p$-nitrophenyl phosphate. All strains were negative for utilization of mannose, trehalose, mannitol, gluconate and sucrose.

\begin{tabular}{|lccccccc|}
\hline Characteristic & $\mathbf{1}$ & $\mathbf{2}$ & $\mathbf{3}$ & $\mathbf{4}$ & $\mathbf{5}$ & $\mathbf{6}$ & $\mathbf{7}$ \\
\hline Utilization as sole carbon & & & & & & & \\
source & & & & & & & \\
D-Glucose & + & - & - & - & + & - & - \\
L-Arabinose & + & - & - & - & - & + & - \\
Adipate & - & - & - & - & - & - & + \\
Lactate & - & - & + & + & + & + & - \\
cis-Aconitate & - & + & - & - & - & - & - \\
Citrate & + & - & - & - & - & - & - \\
DL-3-Hydroxybutyrate & + & + & + & + & + & + & - \\
2-Oxoglutarate & + & + & + & + & + & - & + \\
Pyruvate & + & + & + & + & + & + & + \\
Acetate & - & + & - & + & + & + & + \\
Acid formed from: & & & & & & & \\
Glucose & + & - & - & - & - & - & - \\
Maltose & + & - & - & - & - & - & - \\
Cellobiose & + & - & - & - & - & - & - \\
Aesculin hydrolysis & + & + & + & + & + & + & - \\
ONPG hydrolysis & + & + & + & + & + & - & - \\
& & & & & & &
\end{tabular}

$2 \mu \mathrm{g}$ DNA was labelled during a $3 \mathrm{~h}$ incubation at $15{ }^{\circ} \mathrm{C}$. The results are shown in Table 3.

Examinations based on almost-entire 16S rRNA gene sequences showed affiliation of the six strains to the genus Naxibacter. They also shared the characteristics of the genus (Xu et al., 2005), which are a fatty acid profile consisting of the major compounds $\mathrm{C}_{16: 1} \omega 7 c$ and $\mathrm{C}_{16: 0}$ and the

Table 3. DNA-DNA reassociation (\%) between the novel strains and $N$. alkalitolerans CCUG $50882^{\top}$

\begin{tabular}{|lccccccc|}
\hline Strain & $\mathbf{1}$ & $\mathbf{2}$ & $\mathbf{3}$ & $\mathbf{4}$ & $\mathbf{5}$ & $\mathbf{6}$ & $\mathbf{7}$ \\
\hline $\begin{array}{l}\text { 1. N. alkalitolerans } \\
\text { CCUG 50882 }\end{array}$ & 100 & 62 & 43 & 48 & - & 48 & 23 \\
N. varians & & & & & & & \\
2. CCUG 48018 & 51 & 100 & 94 & - & - & 76 & - \\
3. CCUG 35299 & 39 & 100 & 100 & 100 & 85 & 64 & 30 \\
4. CCUG 49054 & 53 & - & 98 & 100 & - & - & - \\
5. CCUG 24677A & - & - & 100 & - & 100 & - & - \\
6. CCUG 48700A & 54 & 65 & 84 & - & - & 100 & 34 \\
7. N. haematophilus & 28 & - & - & - & - & 19 & 100 \\
CCUG 38318 & & & & & & & \\
\hline
\end{tabular}

- , Not done. 
hydroxylated fatty acids $\mathrm{C}_{10: 0} 3-\mathrm{OH}$ and $\mathrm{C}_{12: 0} 2-\mathrm{OH}$, the main quinone ubiquinone Q-8 (in congruence with that of $N$. alkalitolerans) and a polar lipid profile containing the major compounds phosphatidylglycerol and phosphatidylethanolamine. We could not detect the presence of phosphatidylinositol mannosides, reported to be another major compound in N. alkalitolerans (Xu et al., 2005), in any of the strains classified in this study or in N. alkalitolerans. Hence, we conclude that $\mathrm{Xu}$ et al. (2005) erroneously identified this Gram-positive-characteristic lipid in $N$. alkalitolerans. From our point of view, this error makes an emended description of the genus Naxibacter necessary.

Relationship at the species level of strains CCUG $35299^{\mathrm{T}}$, CCUG 24677A, CCUG 48018, CCUG 49054 and CCUG $48700 \mathrm{~A}$, as indicated by high $16 \mathrm{~S}$ rRNA gene sequence similarities, was confirmed by the results of DNA-DNA hybridizations (Table 3). Strain CCUG $35299^{\mathrm{T}}$ showed only $97.6 \%$ sequence similarity to $N$. alkalitolerans CCUG $50882^{\mathrm{T}}$ but $99 \%$ similarity to strain CCUG $38318^{\mathrm{T}}$. The results from DNA-DNA hybridizations, however, showed that these strains represent distinct species. On the basis of phenotypic traits (physiological properties) and the results of DNA-DNA hybridizations, we describe two novel Naxibacter species.

\section{Description of Naxibacter varians sp. nov.}

Naxibacter varians (va'ri.ans. L. part. adj. varians varying, pertaining to the variable results in biochemical tests).

Cells are non-motile, non-spore-forming rods (approx. $2 \mu \mathrm{m}$ long and $1 \mu \mathrm{m}$ wide). Gram-negative and oxidasepositive, showing an oxidative metabolism. Good growth occurs on R2A agar, TSA, PYE agar, nutrient agar and MacConkey agar at $25-30{ }^{\circ} \mathrm{C}$. Growth is detected on TSA at $15-37{ }^{\circ} \mathrm{C}$; no growth at 10 or $45{ }^{\circ} \mathrm{C}$. Growth is positive in TS broth (TSB) at pH 5.5-10.5 (strain CCUG 48700A is even able to grow at $\mathrm{pH} 11.5$ ). Beige, translucent and shiny colonies with entire edges are formed within $24 \mathrm{~h}$, with a diameter of approximately $2 \mathrm{~mm}$. The quinone system consists of the major compound ubiquinone Q- 8 and small amounts of Q-7. The polyamine pattern contains the predominant compounds putrescine [44.8-69.0 $\mu \mathrm{mol}$ (g dry weight $\left.)^{-1}\right]$ and 2-hydroxyputrescine [26.3-46.3 $\mu \mathrm{mol}$ (g dry weight $\left.)^{-1}\right]$ and variable amounts of spermidine [1.4$\left.16.8 \mu \mathrm{mol}(\mathrm{g} \text { dry weight })^{-1}\right]$ and spermine [1.1-6.0 $\mu \mathrm{mol}$ (g dry weight $\left.)^{-1}\right]$. Trace amounts $[<1.0 \mu \mathrm{mol}$ (g dry weight $)^{-1}$ ] of 1.3-diaminopropane and cadaverine may also be present. The major compounds in the polar lipid profile are phosphatidylethanolamine, phosphatidylglycerol and diphosphatidylglycerol. Moderate amounts of an unknown polar lipid and an unknown phospholipid and minor to trace amounts of two unknown aminolipids and an unknown phospholipid are present. The fatty acid profile is composed largely of $\mathrm{C}_{16: 1} \omega 7 c(45.8-50.4 \%)$ and $\mathrm{C}_{16: 0}(31.9-33.3 \%)$. Carbon-source utilization and hydrolysis of chromogenic substrates (including differentiating characters for all Naxibacter species) are indicated in
Table 2. Sensitive towards polymyxin B (300 U), penicillin G (10 IU), amoxicillin $(25 \mu \mathrm{g})$, amoxicilin/clovalanat $(30 \mu \mathrm{g})$, gentamicin $(10 \mu \mathrm{g})$, trimethoprim $(5 \mu \mathrm{g})$, ciprofloxacin $(5 \mu \mathrm{g})$, rifampicin $(5 \mu \mathrm{g})$ and colistin $(25 \mu \mathrm{g})$.

The type strain CCUG $35299^{\mathrm{T}}\left(=\mathrm{CCM} 7478^{\mathrm{T}}\right)$ was isolated from the eye of a 90-year-old man in Tromsö, Norway. Other strains of this species are CCUG 24677A, CCUG 48018, CCUG 49054 and CCUG 48700A.

\section{Description of Naxibacter haematophilus sp. nov.}

Naxibacter haematophilus (hae.ma.to.phi'lus. Gr. n. haema -atos blood; Gr. adj. philos loving; N.L. masc. adj. haematophilus loving blood, referring to the isolation of the type strain from blood).

Cells are non-motile, non-spore-forming rods (approx. $2 \mu \mathrm{m}$ long and $1 \mu \mathrm{m}$ wide). Gram-negative and oxidasepositive, showing an oxidative metabolism. Good growth occurs on R2A agar, TSA, PYE agar and nutrient agar at 25$30{ }^{\circ} \mathrm{C}$. Growth is detected on TSA at $15-37{ }^{\circ} \mathrm{C}$; no growth at 10 or $45^{\circ} \mathrm{C}$. Growth is positive in TSB at pH 5.5-10.5. Colonies are beige, translucent and shiny with entire edges and form within $24 \mathrm{~h}$, with a diameter of approximately $2 \mathrm{~mm}$. The quinone system consists of the major compound ubiquinone Q-8 and small amounts of Q-7. The polyamine pattern contains the predominant compounds putrescine $\left.[95.9 \mu \mathrm{mol} \text { (g dry weight })^{-1}\right]$ and 2-hydroxyputrescine $\left.[21.0 \mu \mathrm{mol} \text { (g dry weight })^{-1}\right]$ and small amounts $[<3 \mu \mathrm{mol}$ ( $\mathrm{g}$ dry weight $)^{-1}$ ] of spermidine and spermine. The major compounds in the aminolipid profile are phosphatidylethanolamine, phosphatidylglycerol and diphosphatidylglycerol. Moderate amounts of an unknown aminolipid and an unknown aminophospholipid and minor to trace amounts of one unknown aminolipid and three unknown phospholipids are present. The fatty acid profile is composed largely of $\mathrm{C}_{16: 1} \omega 7 c(52.1 \%)$ and $\mathrm{C}_{16: 0}(22.3 \%)$. Carbon-source utilization and hydrolysis of chromogenic substrates (including differentiating characters for all Naxibacter species) are indicated in Table 2. Sensitive towards polymyxin B $(300 \mathrm{U})$, penicillin $\mathrm{G}(10 \mathrm{IU})$, amoxicillin $(25 \mu \mathrm{g})$, amoxicilin/clovalanat $(30 \mu \mathrm{g})$, gentamicin $(10 \mu \mathrm{g})$, trimethoprim $(5 \mu \mathrm{g})$, ciprofloxacin $(5 \mu \mathrm{g})$, rifampicin $(5 \mu \mathrm{g})$ and colistin $(25 \mu \mathrm{g})$.

The type strain CCUG $38318^{\mathrm{T}}\left(=\mathrm{CCM} 7480^{\mathrm{T}}\right)$ was isolated in 1997 from blood of a 23-year-old man with multiple health problems.

\section{Emended description of the genus Naxibacter Xu et al. 2005}

The description is that of $\mathrm{Xu}$ et al. (2005), with the exception that the polar lipid profile does not contain phosphatidylinositol mannosides. Another lipid present in major amounts is diphosphatidylglycerol. The polyamine pattern contains the predominant compounds 2-hydroxyputrescine and putrescine. 


\section{Acknowledgements}

We are grateful to the laboratories in Lund and Stockholm, Sweden, and Tromsö, Norway, and to the two industries for submitting their isolates and to the entire CCUG staff for their devoted work.

\section{References}

Altenburger, P., Kämpfer, P., Makristathis, A., Lubitz, W. \& Busse, H.-J. (1996). Classification of bacteria isolated from a medieval wall painting. J Biotechnol 47, 39-52.

Busse, H.-J. \& Auling, G. (1988). Polyamine pattern as a chemotaxonomic marker within the Proteobacteria. Syst Appl Microbiol 11, 1-8.

Busse, H.-J., Bunka, S., Hensel, A. \& Lubitz, W. (1997). Discrimination of members of the family Pasteurellaceae based on polyamine patterns. Int J Syst Bacteriol 47, 698-708.

Busse, H.-J., Hauser, E. \& Kämpfer, P. (2005). Description of two novel species, Sphingomonas abaci sp. nov. and Sphingomonas panni sp. nov. Int J Syst Evol Microbiol 55, 2565-2569.

Gerhardt, P., Murray, R. G. E., Wood, W. A. \& Krieg, N. R. (editors) (1994). Methods for General and Molecular Bacteriology. Washington, DC: American Society for Microbiology.

Kämpfer, P. \& Kroppenstedt, R. M. (1996). Numerical analysis of fatty acid patterns of coryneform bacteria and related taxa. Can J Microbiol 42, 989-1005.

Kämpfer, P., Steiof, M. \& Dott, W. (1991). Microbiological characterization of a fuel-oil contaminated site including numerical identification of heterotrophic water and soil bacteria. Microb Ecol 21, 227-251.

Kämpfer, P., Dreyer, U., Neef, A., Dott, W. \& Busse, H.-J. (2003). Chryseobacterium defluvii sp. nov., isolated from wastewater. Int J Syst Evol Microbiol 53, 93-97.

Kumar, S., Tamura, K., Jakobsen, I.-B. \& Nei, M. (2001). MEGA2: molecular evolutionary genetics analysis software. Bioinformatics $\mathbf{1 7}$, 1244-1245.

Ludwig, W., Strunk, O., Westram, R., Richer, L., Meier, H., Yadhukumar, Buchner, A., Lai, T., Steppi, S. \& other authors (2004). ARB: a software environment for sequence data. Nucleic Acids Res 32, 1363-1371.

Thompson, J. D., Gibson, T. J., Plewniak, F., Jeanmougin, F. \& Higgins, D. G. (1997). The CLUSTAL_X windows interface: flexible strategies for multiple sequence alignment aided by quality analysis tools. Nucleic Acids Res 25, 4876-4882.

Tindall, B. J. (1990a). Lipid composition of Halobacterium lacusprofundi. FEMS Microbiol Lett 66, 199-202.

Tindall, B. J. (1990b). A comparative study of the lipid composition of Halobacterium saccharovorum from various sources. Syst Appl Microbiol 13, 128-130.

Xu, P., Li, W. J., Tang, S. K., Zhang, Y. Q., Chen, G.-Z., Chen, H.-H., Xu, L. H. \& Jiang, C. L. (2005). Naxibacter alkalitolerans gen. nov., sp. nov., a novel member of the family 'Oxalobacteraceae' isolated from China. Int J Syst Evol Microbiol 55, 1149-1153.

Ziemke, F., Höfle, M. G., Lalucat, J. \& Rosselló-Mora, R. (1998). Reclassification of Shewanella putrefaciens Owen's genomic group II as Shewanella baltica sp. nov. Int J Syst Bacteriol 48, 179-186. 